\title{
Effect of Acute Increase in Intracranial Pressure on Blood Flow in the Internal Carotid Artery of Man*
}

\author{
Joseph C. Greenfield, JR.,† and George T. Tindall \\ (From the Departments of Medicine and Surgery, Division of Neurosurgery, Duke University' \\ Medical Center and Durham Veterans Administration Hospital, \\ Durham, N.C.)
}

The cardiovascular effects resulting from an acute elevation in cerebrospinal fluid (CSF) pressure to levels higher than arterial blood pressure were fully described by Cushing and are well known $(1,2)$. However, the extent to which intracranial blood flow is altered by moderate increases in CSF pressure has not been fully clarified. Using a plethysmographic method of measuring cerebral blood flow in two subjects, Ferris found a decrease in flow following acute elevation of the CSF pressure above $350 \mathrm{~mm} \mathrm{H} \mathrm{H}_{2} \mathrm{O}$ (3). Kety, Shenkin, and Schmidt measured cerebral blood flow (nitrous oxide technique) in 13 patients and found that flow was uniformly depressed in patients having a CSF pressure greater than $450 \mathrm{~mm} \mathrm{H}_{2} \mathrm{O}$ (4). On the other hand, Green, Rapela, and Conrad recently stated, "Artificially induced changes of cerebrospinal fluid pressure have little effect on flow unless the pressure is elevated above arterial pressure" (5). Similarly, Williams and Lennox found that moderately elevated levels of CSF pressure had no significant effect on cerebral blood flow (6).

Since the results of the foregoing investigations are conflicting, a quantitative evaluation of the relation between the level of CSF pressure and cerebral blood flow should be of interest. The purpose of the present study was to measure the effects of incremental increases in CSF pressure on the human cerebral circulation.

* Submitted for publication February 10, 1965; ac. cepted April 22, 1965.

Supported in part by a grant from the North Carolina Heart Association (1964).

Presented in part at the annual meeting of the Academy of Neurological Sciences, Key Biscayne, Fla., November 1964.

† Address requests for reprints to Dr. Joseph C. Greenfield, Jr., Veterans Administration Hospital, Fulton Street and Erwin Road, Durham, N. C.

\section{Methods}

The blood flow studies were carried out in 13 male patients who were undergoing surgical exposure of the carotid artery so that an antitumor agent ${ }^{1}$ could be infused directly into the internal carotid artery. In each subject craniotomy and subtotal resection of a supratentorial brain tumor had been performed from 10 to 14 days before the study. The histologic diagnoses were as follows: glioblastoma multiforme, five cases; astrocytoma, seven cases; and oligodendroglioma, one case.

The surgical procedure on the neck was done with general anesthesia (a mixture of halothane, $0.5 \%$; nitrous oxide, $49.5 \%$; and oxygen, $50 \%$ ). The common carotid and proximal portions of the external and internal carotid arteries were exposed. A $10-\mathrm{cm}$ long polyvinyl catheter ${ }^{2}$ was inserted into the superior thyroid artery and advanced until the tip was within the bifurcation of the common carotid artery. The remaining branches of the external carotid artery were then ligated. The probe of a KolinKado type electromagnetic flowmeter ${ }^{3}$ (E.M.F.) (7) was placed around the common carotid artery approximately 4 $\mathrm{cm}$ proximal to the bifurcation. A Crutchfield clamp 4 was also placed about this vessel distal to the E.M.F. probe. The stem of the Crutchfield clamp, the polyvinyl catheter, and the E.M.F. probe leads were brought out through the incision, which was closed in anatomic layers with silk sutures. The experimental data were obtained with the patient in the lateral recumbent position 2 to 8 hours after general anesthesia had been discontinued. The patients were awake and had received no additional medications before the study.

Blood flow was measured with the Kolin-Kado type E.M.F. Both pulsatile and mean flows were recorded. The time constant for the mean flow network was 3.5 seconds, and the frequency response of the E.M.F. was flat $\pm 5 \%$ through at least 20 cycles per second. A zero flow reference was obtained by temporarily occluding the artery with the Crutchfield clamp. The E.M.F. was calibrated following each procedure by passing known quan-

$1 \mathrm{~S}-112$ (a chlorethylthioacetomide) was given in a dosage of $0.08 \mathrm{mg}$ per $\mathrm{kg}$ body weight.

2 No. VX-044, Becton, Dickinson, Rutherford, N. J.

3 Model K-2000, Medicon, Los Angeles, Calif.

4 A small surgical screw clamp used for gradual occlusion of the carotid artery in the treatment of intracranial aneurysms. 
tities of physiologic saline through the probe in a given period of time. The calibration factor for the probes, i.e., flow per unit E.M.F. signal, remained within a $\mathrm{SD} \pm$ $5.4 \%$ during the period of this study. Arterial pressure was measured with a Statham P23Db strain gauge connected directly to the polyvinyl catheter. The frequency response of this system was flat $\pm 5 \%$ through 20 cycles per second.

Two lumbar punctures were performed in the usual manner with 18-gauge lumbar puncture needles at the fourth lumbar and fifth lumbar interspaces, respectively. One needle was connected to a Statham P23Db strain gauge via a short plastic tube. The second needle was connected to a bottle containing sterile Ringer's solution. The level of the CSF pressure could then be controlled by adjusting the height of this container. The zero reference for both arterial pressure and CSF pressure was assumed to be at the level of the spinal axis. The frequency response of this system was similar to that used to measure arterial pressure.

An electrocardiogram, usually lead two, was recorded throughout the procedure. Also in each patient an electroencephalogram using a standard $\mathrm{H}$ run was obtained during the procedure with needle electrodes in the scalp and was recorded on an eight-channel electroencephalograph. 5

During the control period, in order to assess the physiologic state of the subjects, brachial arterial samples were drawn for measurement of $\mathrm{PCO}_{2}$ and arterial oxygen saturation. ${ }^{6}$ Also, the cardiac output was obtained in the control state by the indicator dilution technique. ${ }^{7}$ Indocyanine green dye was injected into the median basillic vein and sampled from the brachial artery. All recording of data except for the electroencephalogram was carried out on a direct writing oscillograph. 8

After obtaining control readings, the CSF pressure was altered by adjusting the height of the container of Ringer's solution. Usually the level of CSF pressure was decreased to normal in those patients who had an elevated initial pressure, i.e., "opening pressure." The CSF pressure was then increased in increments of 100 to $200 \mathrm{~mm}$ $\mathrm{H}_{2} \mathrm{O}$ during a 2- to 3-minute period to a level of approximately $1,000 \mathrm{~mm} \mathrm{H}_{2} \mathrm{O}$. The time required to achieve the maximal CSF pressure was approximately 5 minutes. This value was lower than the patient's diastolic blood pressure in all cases. The CSF pressure was maintained at its maximal elevation for 3 to 5 minutes and then was gradually decreased to normal levels. Upon completion of the study, the cancer chemotherapy drug was infused, and the patients were returned to the operating room for removal of the Crutchfield clamp, E.M.F. probe, and intra-arterial catheter.

In every subject mean and pulsatile values for CSF

5 Grass electroencephalograph, model SF-330P4, Quincy, Mass.

${ }^{6}$ Meter model 113, Instrumentation Laboratories, Boston, Mass.

7 Colson densitometer, Colson Corp., Elyria, Ohio.

${ }^{8}$ Recorder model 850, Sanborn Co., Cambridge, Mass. pressure, carotid blood pressure, and internal carotid blood flow were obtained during the control state and following each incremental change in CSF pressure. These data were calculated as the average values measured in three to five consecutive cardiac cycles. Mean values of both blood pressure and CSF pressure were obtained by adding one-third of the respective pulse pressure values to the diastolic pressure. Standard statistical methods were employed in evaluating the data (8).

To further evaluate the pattern of filling of the intracranial circulation during elevated CSF pressure, cerebral angiography was carried out in three additional patients both during control and increased CSF pressure induced by infusion of Ringer's solution in the lumbar subarachnoid space as described above. Serial lateral exposures of the skull were made at 0.75 -second intervals following a rapid injection of $12 \mathrm{ml}$ of $50 \%$ sodium diatrizoate ${ }^{9}$ into the right common carotid artery. The angiographic exposures were made with an automatic film' changer ${ }^{10}$ during a 20-second period. One injection of contrast media was made at control CSF pressure and a second injection made while the mean CSF pressure was elevated to a level just under the patient's diastolic blood pressure.

\section{Results}

Pertinent data obtained in these subjects before altering the CSF pressure are given in Table I. In 12 of the subjects the "opening," i.e., initial, CSF pressure was elevated (mean $299 \mathrm{~mm} \mathrm{H}_{2} \mathrm{O}$, $\mathrm{SE} \pm 22$ ). The mean cardiac output for the group was $6,662 \mathrm{~cm}^{3}$ per minute, $\mathrm{SE} \pm 320$. The arterial $\mathrm{PCO}_{2}$ and arterial oxygen saturation values for the group were $38.9 \mathrm{~mm} \mathrm{Hg}, \mathrm{SE} \pm 1.3$, and $93.4 \%, \mathrm{SE} \pm 0.5$, respectively.

In eight subjects the CSF pressure was reduced to normal levels. Blood flow was essentially unaffected by this reduction in CSF pressure except for patient W.McK. In this patient flow increased $15 \mathrm{~cm}^{3}$ per minute following CSF pressure reduction. The lowest CSF pressure in each subject (Table II A, column 1) had a mean value of 190 $\mathrm{mm} \mathrm{H}_{2} \mathrm{O}, \mathrm{SE} \pm 13$. At this CSF pressure level the maximal value for flow in the internal carotid artery, i.e., peak flow, had an average value of 7.1 $\mathrm{cm}^{3}$ per second, and the minimal value for forward flow had an average value for the group of $1.5 \mathrm{~cm}^{3}$ per second (Table II A, column 2 ). The mean value for flow was $201 \mathrm{~cm}^{3}$ per minute, $\mathrm{SE} \pm$ 16. Average systolic and diastolic blood pressures were 124 and $75 \mathrm{~mm} \mathrm{Hg}$, respectively. Mean arterial blood pressure was $92 \mathrm{~mm} \mathrm{Hg}, \mathrm{SE} \pm 3$, for

\footnotetext{
${ }^{9}$ Hypaque, Winthrop Laboratories, New York, N. Y. 10 Elema-Schönander, Stockholm, Sweden.
} 
TABLE I

General data

\begin{tabular}{|c|c|c|c|c|c|}
\hline Name & $\begin{array}{l}\text { (1) } \\
\text { Age }\end{array}$ & $\begin{array}{c}\text { (2) } \\
\text { "Opening" } \\
\text { CSF } \\
\text { pressure* }\end{array}$ & $\begin{array}{c}\text { (3) } \\
\text { Cardiac } \\
\text { output }\end{array}$ & $\begin{array}{c}(4) \\
\text { Arterial } \\
\text { PcO2 }\end{array}$ & $\begin{array}{c}(5) \\
\mathrm{O}_{2} \text { saturation } \\
\text { Arterial }\end{array}$ \\
\hline & years & $m m \mathrm{H}_{2} \mathrm{O}$ & $\mathrm{cm}^{2} / \min$ & $m m H g$ & $\%$ \\
\hline K.P. & 50 & 263 & 5,836 & 32.8 & 95.3 \\
\hline J. B. & 72 & 222 & 4,520 & 38.0 & 93.0 \\
\hline $\mathrm{O} . \mathrm{P}$. & 39 & 167 & 6,713 & 39.2 & 94.4 \\
\hline W. L. & 36 & 300 & 7,051 & 36.8 & 94.0 \\
\hline L. A. & 52 & 358 & & 38.6 & 91.5 \\
\hline I. $\mathrm{H}$. & 63 & 303 & 5,510 & 35.5 & 91.5 \\
\hline G. H. & 48 & 240 & 8,446 & 44.0 & 93.0 \\
\hline W. McK. & 38 & 448 & 7,327 & & \\
\hline Z. L. & 37 & 330 & 5,711 & 42.5 & 94.5 \\
\hline G. E. & 37 & 426 & 6,956 & 48.0 & 95.0 \\
\hline K. B. & 53 & 263 & 6,907 & 41.5 & 91.7 \\
\hline R. $\mathrm{H}$. & 48 & 330 & 6,892 & 36.0 & 93.2 \\
\hline C. W. & 42 & 235 & 8,080 & 33.8 & 94.5 \\
\hline $\begin{array}{l}\text { Mean } \\
\text { SE }\end{array}$ & $\begin{array}{r}47 \\
+3\end{array}$ & $\begin{array}{r}299 \\
+\quad 22\end{array}$ & $\begin{array}{r}6,662 \\
+\quad 320\end{array}$ & $\begin{array}{r}38.9 \\
+\quad 1.3\end{array}$ & $\begin{array}{r}93.4 \\
+\quad 0.5\end{array}$ \\
\hline
\end{tabular}

${ }^{*} \mathrm{CSF}=$ cerebrospinal fluid.

the group (Table II A, column 3). Mean heart rate was 93 beats per minute, $\mathrm{SE} \pm 3$ (Table II $\mathrm{A}$, column 4). At a mean CSF pressure level of 380 $\mathrm{mm} \mathrm{H}_{2} \mathrm{O}, \mathrm{SE} \pm 11$, flow for the group had decreased by approximately $4 \%$ to $193 \mathrm{~cm}^{3}$ per minute, $\mathrm{SE} \pm 16$ (Table II B, columns 5 and 6 ). At this CSF pressure flow was significantly decreased $(\mathrm{p}<.01)$ for the entire group. In Table II C, columns 7 and 8, data are listed that were obtained during moderate elevation of the CSF pressure. The mean CSF pressure was $594 \mathrm{~mm} \mathrm{H}_{2} \mathrm{O}, \mathrm{SE} \pm$ 16 , and the mean flow was $171 \mathrm{~cm}^{3}$ per minute, $\mathrm{SE} \pm 14$.

The last four columns in Table II contain data obtained at the highest value of CSF pressure for each patient. The mean value of CSF pressure was $920 \mathrm{~mm} \mathrm{H}_{2} \mathrm{O}, \mathrm{SE} \pm 46$ (Table II D, column 9). At this CSF pressure level, the pulsatile flow has an average maximal value of $6.4 \mathrm{~cm}^{3}$ per second and a minimal of $0.6 \mathrm{~cm}^{3}$ per second. The average flow for the group had a mean of $148 \mathrm{~cm}^{3}$ per minute, $\mathrm{SE} \pm 15$ (Table II $\mathrm{D}$, column 10), representing a decrease of $25 \%$ from the control flow. Both blood pressure and heart rate were essentially unchanged during elevation of the CSF pressure (see Table II D, columns 11 and 12, respectively).

The effect of incremental increases in CSF pressure on mean internal carotid arterial blood flow is graphically illustrated in Figure 1. In this
Figure, values for CSF pressure divided by control CSF pressure appear on the abscissa, and values for flow divided by control flow are given on the ordinate. This graph was calculated by selecting from each subject approximately ten values

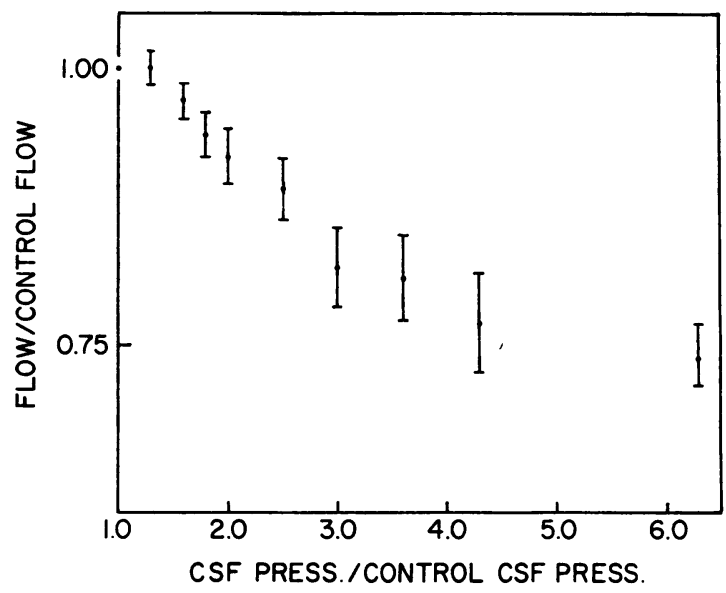

Fig. 1. RELATION BETWEEN INTERNAL CAROTID ARTERIAL BLOOD FLOW AND CEREBROSPINAL FLUID (CSF) PRESSURE. The data were normalized by first dividing values of both flow and CSF pressure by each patient's control values, and then clustering them in groups of ten along both the ordinate and abscissa. The vertical bars represent the standard error. Note that flow tends to decrease at 1.6 times the control CSF pressure, and at 1.8 times control CSF pressure flow is significantly decreased $(\mathrm{p}<.01)$. As described in the text the mean arterial pressure remained constant during these measurements. 
TABLE II

Pressure and

\begin{tabular}{|c|c|c|c|c|c|c|c|c|}
\hline \multirow[b]{3}{*}{ Name } & \multicolumn{6}{|c|}{ A } & \multicolumn{2}{|c|}{ B } \\
\hline & \multirow{2}{*}{$\underset{\text { pressure }}{\stackrel{(1)}{\text { CSF }}}$} & \multicolumn{2}{|c|}{$\begin{array}{c}\text { (2) } \\
\text { Blood flow }\end{array}$} & \multicolumn{2}{|c|}{$\begin{array}{c}(3) \\
\text { Blood pressure }\end{array}$} & \multirow{2}{*}{$\begin{array}{l}(4) \\
\text { Heart } \\
\text { rate }\end{array}$} & \multirow{2}{*}{$\underset{\text { pressure }}{\stackrel{(5)}{\text { CSF }}}$} & \multirow{2}{*}{$\begin{array}{l}\text { (6) } \\
\text { Blood flow } \\
\text { Mean }\end{array}$} \\
\hline & & $\begin{array}{r}\text { Bloo } \\
\mathrm{Max} / \min \dagger\end{array}$ & Mean & $\begin{array}{r}\text { Blood } \\
\text { Syst/diast }\end{array}$ & $\begin{array}{l}\text { sure } \\
\text { Mean }\end{array}$ & & & \\
\hline & $\mathrm{mm} \mathrm{H}_{2} \mathrm{O}$ & $\mathrm{cm}^{8} / \mathrm{sec}$ & $\mathrm{cm}^{8} / \min$ & \multicolumn{2}{|c|}{$m m \mathrm{Hg}$} & beats/min & $\mathrm{mm} \mathrm{H}_{2} \mathrm{O}$ & $\mathrm{cm}^{3} / \min$ \\
\hline K. P. & 263 & $10.4 / 1.7$ & 207 & $124 / 84$ & 97 & 90 & 412 & 202 \\
\hline J. B. & 222 & $3.5 / 0.3$ & 97 & $108 / 64$ & 79 & 114 & 412 & 90 \\
\hline $\mathrm{O} . \mathrm{P}$. & 167 & $4.6 / 0.6$ & 194 & $132 / 88$ & 103 & 98 & 303 & 184 \\
\hline W. L. & 200 & $8.8 / 0$ & 133 & $136 / 84$ & 100 & 90 & 439 & 125 \\
\hline L. A. & 127 & $8.3 / 2.1$ & 244 & $144 / 92$ & 109 & 110 & 358 & 230 \\
\hline I. $\mathrm{H}$. & 168 & $10.5 / 1.7$ & 255 & $116 / 56$ & 76 & 78 & 385 & 242 \\
\hline G. H. & 140 & $8.5 / 2.6$ & 287 & $128 / 80$ & 96 & 90 & 358 & 277 \\
\hline W. M cK. & 140 & $8.1 / 2.7$ & 229 & $132 / 58$ & 79 & 84 & 381 & 216 \\
\hline Z. L. & 195 & $7.3 / 1.7$ & 173 & $118 / 78$ & 92 & 70 & 340 & 167 \\
\hline G. E. & 150 & $5.3 / 1.3$ & 172 & $120 / 84$ & 96 & 90 & 435 & 157 \\
\hline K. B. & 263 & $5.2 / 1.4$ & 277 & $114 / 80$ & 91 & 102 & 371 & 270 \\
\hline R. H. & 201 & $4.2 / 1.1$ & 142 & $142 / 76$ & 98 & 96 & 340 & 138 \\
\hline C. W. & 235 & $7.0 / 2.5$ & 206 & $104 / 60$ & 75 & 102 & 407 & 203 \\
\hline Mean & 190 & $7.1 / 1.5$ & 201 & $124 / 75$ & 92 & 93 & 380 & 193 \\
\hline $\mathrm{SE}$ & \pm 13 & & \pm 16 & & \pm 3 & \pm 3 & \pm 11 & \pm 16 \\
\hline
\end{tabular}

*A, data obtained at the lowest CSF pressure; B, CSF pressure and flow measurements obtained when flow first significantly decreases; C, CSF pressure and flow measurements during moderate CSF pressure elevation; D, data obtained at the highest CSF pressure.

$\dagger \mathrm{Max} / \mathrm{min}=$ maximal and minimal values of flow.

$\ddagger$ Syst/diast $=$ systolic and diastolic blood pressure.

for mean flow measured at different levels of CSF pressure. To normalize the data, both CSF pressure and flow values were divided by that particular subject's control CSF pressure and flow, respectively. The data were then clustered along both the abscissa and ordinate in groups of ten. As can be seen in Figure 1, the flow is not significantly altered until the CSF pressure is approximately 1.8 times the control value. Flow then decreases as the CSF pressure rises. The small vertical bars represent the standard error.

As described in the Methods section, the CSF pressure was maintained at its highest level for from 3 to 5 minutes in each patient. In nine patients the mean internal carotid arterial flow remained essentially constant during this time. In four subjects, however (Table II, patients W.L., I.H., G.H., and Z.L.), the flow increased slightly (15 to $20 \mathrm{~cm}^{3}$ per second) during this time in spite of a relatively constant CSF and blood pressure. It should be noted that the values for flow listed in Table II for these four subjects are the lowest values obtained.

The lowest CSF pulse pressure had a mean value for the group of $15 \mathrm{~mm} \mathrm{H}_{2} \mathrm{O}, \mathrm{SE} \pm 2$ (Table III, column 2). This value was only $2.5 \%$ of the mean

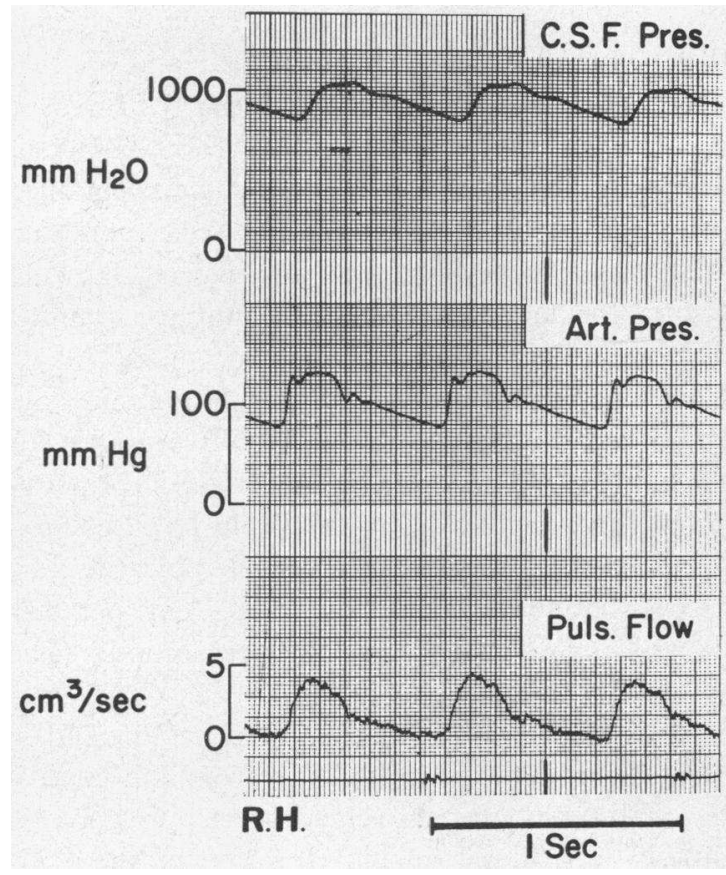

Fig. 2. From the TOP DOWN : CSF PRESSURE, ARTERIAL PRESSURE, AND PULSATILE FLOW. Note the similarity in the contours of CSF pressure and arterial pressure. It is apparent that at a mean CSF pressure of $950 \mathrm{~mm} \mathrm{H}_{2} \mathrm{O}$, there is no flow at the end of diastole. 
TABLE $1 \mathrm{I}$

flow data*

\begin{tabular}{|c|c|c|c|c|c|c|c|}
\hline \multicolumn{2}{|c|}{$\mathrm{C}$} & \multicolumn{6}{|c|}{ D } \\
\hline \multirow{2}{*}{$\underset{\text { pressure }}{\stackrel{(7)}{C S F}}$} & \multirow{2}{*}{$\begin{array}{l}\text { (8) } \\
\text { Blood } \\
\text { flow } \\
\text { Mean }\end{array}$} & \multirow{2}{*}{$\begin{array}{c}(9) \\
\text { CSF } \\
\text { pressure }\end{array}$} & \multicolumn{2}{|c|}{$\begin{array}{c}\text { (10) } \\
\text { Blood flow }\end{array}$} & \multicolumn{2}{|c|}{$\begin{array}{c}(11) \\
\text { Blood pressure }\end{array}$} & \multirow{2}{*}{$\begin{array}{l}(12) \\
\text { Heart } \\
\text { rate }\end{array}$} \\
\hline & & & $\operatorname{Max} / \min \dagger$ & Mean & Syst/diast* & Mean & \\
\hline$m m \mathrm{H}_{2} \mathrm{O}$ & $\mathrm{cm}^{3} / \min$ & $m m \mathrm{H}_{2} \mathrm{O}$ & $\mathrm{cm}^{2} / \mathrm{sec}$ & $\mathrm{cm}^{2} / \min$ & \multicolumn{2}{|c|}{$m m H g$} & beats/min \\
\hline 548 & 186 & 820 & $6.9 / 1.4$ & 171 & $132 / 84$ & 100 & 84 \\
\hline 657 & 69 & 885 & $2.9 / 0.3$ & 49 & $108 / 68$ & 82 & 114 \\
\hline 657 & 174 & 1,038 & $4.0 / 0.1$ & 146 & $128 / 88$ & 101 & 100 \\
\hline 625 & 120 & 1,119 & $7.7 / 0$ & 85 & $120 / 84$ & 96 & 90 \\
\hline 500 & 212 & 1,174 & $6.5 / 0.6$ & 161 & $148 / 96$ & 113 & 110 \\
\hline 630 & 204 & 810 & $9.5 / 1.0$ & 194 & $120 / 60$ & 80 & 82 \\
\hline 603 & 247 & 1,038 & $9.2 / 0.8$ & 238 & $136 / 84$ & 101 & 86 \\
\hline 589 & 210 & 644 & $7.6 / 1.9$ & 208 & $132 / 58$ & 79 & 84 \\
\hline 521 & 125 & 1,038 & $6.6 / 0.7$ & 120 & $120 / 80$ & 93 & 74 \\
\hline 598 & 156 & 707 & & 150 & $120 / 84$ & 96 & 96 \\
\hline 521 & 215 & 984 & $5.0 / 0.3$ & 175 & $116 / 82$ & 93 & 102 \\
\hline 680 & 112 & 950 & $4.1 / 0$ & 103 & $142 / 76$ & 98 & 102 \\
\hline 591 & 189 & 750 & $6.2 / 1.0$ & 129 & $100 / 60$ & 73 & 102 \\
\hline 594 & 171 & 920 & $6.4 / 0.6$ & 148 & $124 / 77$ & 93 & 94 \\
\hline \pm 16 & \pm 14 & $\pm \quad 46$ & & \pm 15 & & \pm 3 & \pm 3 \\
\hline
\end{tabular}

arterial pulse pressure of $663 \mathrm{~mm} \mathrm{H}_{2} \mathrm{O}, \mathrm{SE} \pm 45$ (Table III, column 1). At the time that internal carotid arterial blood flow was significantly decreased, the mean CSF pulse pressure was $73 \mathrm{~mm}$ $\mathrm{H}_{2} \mathrm{O}, \mathrm{SE} \pm 5$ (Table III, column 3). The highest
CSF pulse pressure showed a mean value of 236 $\mathrm{mm} \mathrm{H}_{2} \mathrm{O}, \mathrm{SE} \pm 31$, or $36 \%$ of the mean arterial pulse pressure (Table III, column 4). In Figure 2 a marked resemblance between the carotid arterial pressure pulse and the highest CSF pressure

TABLE III

Relation of CSF pulse pressure to arterial pulse pressure*

\begin{tabular}{|c|c|c|c|c|}
\hline Name & $\begin{array}{c}\text { (1) } \\
\text { Arterial } \\
\text { pulse pressure }\end{array}$ & $\begin{array}{c}\text { (2) } \\
\text { Lowest CSF } \\
\text { pulse pressure }\end{array}$ & $\begin{array}{l}\text { (3) } \\
\text { CSF pulse pres- } \\
\text { sure when flow } \\
\text { first decreases }\end{array}$ & $\begin{array}{c}\text { (4) } \\
\text { Highest CSF } \\
\text { pulse pressure }\end{array}$ \\
\hline $\begin{array}{l}\text { K. P. } \\
\text { J. B. } \\
\text { O. P. } \\
\text { W. L. } \\
\text { L. A. } \\
\text { I. H. } \\
\text { G. H. } \\
\text { W. McK. } \\
\text { Z. L. } \\
\text { G. E. } \\
\text { K. B. } \\
\text { R. H. } \\
\text { C. W. }\end{array}$ & $\begin{array}{r}\boldsymbol{m} \boldsymbol{H} \mathrm{H}_{2} \mathrm{O} \\
\mathbf{5 4 4} \\
\mathbf{5 9 8} \\
598 \\
707 \\
707 \\
816 \\
652 \\
1,006 \\
544 \\
489 \\
462 \\
897 \\
598\end{array}$ & $\begin{array}{r}m m H_{2} O \\
8 \\
19 \\
14 \\
19 \\
7 \\
22 \\
8 \\
7 \\
27 \\
20 \\
14 \\
16 \\
16\end{array}$ & $\begin{array}{r}m m H_{2} O \\
68 \\
81 \\
68 \\
61 \\
54 \\
109 \\
81 \\
40 \\
68 \\
54 \\
95 \\
95 \\
81\end{array}$ & 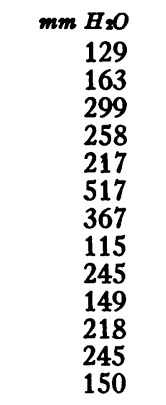 \\
\hline Mean & 663 & 15 & 73 & 236 \\
\hline SE & $\pm \quad 45$ & \pm 2 & \pm 5 & \pm 31 \\
\hline
\end{tabular}

* CSF pulse pressures in columns 2,3, and 4 correspond to the mean CSF pressure data given in Table II, columns 1,5 , and 9 , respectively. 
pulse is illustrated. Note that the upstroke of CSF pressure pulse occurs approximately 0.08 second after the carotid arterial pressure pulse.

During the entire procedure, the patients' level of consciousness was unchanged and they remained asymptomatic. No significant alterations occurred in either the ECG or the EEG recordings.

The cerebral angiographic studies carried out at both normal and elevated CSF pressures clearly demonstrated that although circulation of contrast media was somewhat retarded at the elevated CSF pressure, the entire venous system filled adequately. This included the cortical bridging veins that drain into the superior sagittal sinus and the deep cerebral veins (internal cerebral, basal vein of Rosenthal), as well as those veins on the lateral surface of the cerebral hemisphere (vein of Labbé, middle cerebral vein, and so forth).

\section{Discussion}

Although the patients used in this series had significant intracranial pathology, at the time of study they were alert and had no striking neurologic deficit. It is our contention that the conclusions regarding the effect of increased CSF pressure on internal carotid arterial flow are qualitatively applicable to the normal human subject.

It is difficult to compare the values of blood flow measured with an electromagnetic flowmeter with cerebral blood flow data obtained by other techniques, since most other methods estimate total cerebral blood flow per $100 \mathrm{~g}$ brain weight. However, in the absence of vascular disease, if the internal carotid artery can be assumed to carry onethird of the arterial inflow to the brain (9), then the average value for total cerebral blood flow in our group was approximately $600 \mathrm{~cm}^{3}$ per minute. This figure can be compared to a cerebral blood flow of approximately $54 \mathrm{~cm}^{3}$ per minute per $100 \mathrm{~g}$ brain weight $\left(700 \mathrm{~cm}^{3}\right.$ per minute for an average adult) computed by the nitrous oxide technique in normal subjects (10). In our patients, as a result of the intracranial pathology, the flow may be somewhat less than in normal subjects. During the control state a surprisingly large per cent of the flow in the internal carotid artery was found to be continuous or nonpulsatile in nature (Table II A, column 2). The lowest value for forward flow obtained in each patient had an average value of $1.5 \mathrm{~cm}^{3}$ per second, or $90 \mathrm{~cm}^{3}$ per minute. Thus, almost one-half of the total cerebral blood flow is nonpulsatile. However, the relatively rapid heart rate present in our patients may be partially responsible for this finding. The high level of continuous flow noted in the internal carotid artery is in contrast to flow in the human femoral artery, in which forward flow is usually absent at the end of diastole during the control state (11).

To evaluate the effects of increasing CSF pressure on the carotid arterial blood flow, it must be assumed that the changes in CSF pressure are transmitted equally throughout the subarachnoid space. In the present study, pressure within the intracranial subarachnoid space was not measured. However, Evans has shown an excellent correlation between CSF pressure measured in the lumbar subarachnoid space and in the lateral ventricle of man (12). Furthermore, recent studies carried out in rhesus monkeys by Weinstein, Langfitt, and Kassell demonstrated that pressure in the intracranial subarachnoid space is similar to that found in the lumbar subarachnoid space following an increase in CSF pressure induced by a technique similar to that used in our patients (13). Thus, it seems reasonable to assume that the increase in CSF pressure is distributed equally throughout the subarachnoid space.

The data obtained in the present study clearly demonstrate that in the human subject acute elevation of CSF pressure to levels below the arterial blood pressure results in a moderate decrease in internal carotid arterial blood flow that persists for at least 5 minutes. This finding is in agreement with the previously noted studies of both Kety and co-workers (4) and Ferris (3). In most patients the decrease in flow primarily occurs in the continuous portion of flow, and the pulsatile flow is relatively unaffected. Thus, the average peak to nadir amplitudes of the flow pulse were 5.6 $\mathrm{cm}^{3}$ per second in the control state and $5.8 \mathrm{~cm}^{3}$ per second at the highest level of CSF pressure (see Table II, columns 2 and 10).

The mechanical effects of increasing CSF pressure on cerebral blood flow can be at least partially explained by comparing the cerebral circulation to a physical model consisting of a collapsible tube enclosed within a rigid box as proposed by Kety and co-workers (4). The flow rate through this tube is proportional to the pressure drop between 
the inflow pressure and the pressure within the box, provided this latter pressure is higher than the outflow pressure. Furthermore, pressure within the tube just proximal to the outflow end of the tube will be equal to the surrounding pressure. A more complete description of this physical model and a discussion of the concepts of the "vascular waterfall" as it may apply to the circulation in general have been given by Permutt and Riley (14). The major details of the cerebral circulation seem to conform to the above model. Many of the veins that drain the brain lie freely within the subarachnoid space and would appear to be easily collapsible (15). To remain patent, pressure within these veins must be at least equal to the surrounding CSF pressure. It has been repeatedly demonstrated in the experimental animal that an increase in CSF pressure does not elevate pressure within the venous sinuses, and it is reasonable that this finding would be applicable to man $(13,15)$. As the $\mathrm{CSF}$ pressure is elevated, pressure within the subarachnoid veins must increase or they will collapse. Thus, a pressure drop will occur near the point of entry of these veins into the venous sinuses. That the veins are not collapsed was demonstrated in our patients who were angiographically found to have a normally dilated venous system even when the CSF pressure was markedly elevated. In earlier studies carried out on dogs, Wright observed the confluence of the cortical veins and the sagittal sinus through a "window" (16). $\mathrm{He}$ noted that as the CSF pressure was raised the small veins did not collapse until the systolic blood pressure level was reached. Furthermore, a "cuff constriction" appeared at the junction of these veins with the sinus.

Thus, as a first approximation we may characterize the cerebral circulation as containing two major loci of resistance, one located at the arteriolar-capacity level and the other at the entrance of the cerebral veins into the venous sinuses. Normally the latter probably has little effect on regulating cerebral blood flow. However, as the CSF pressure is increased, this area of resistance becomes the primary point of pressure drop within the cerebral circulation. Furthermore, cerebral blood flow will be reduced proportionately as the effective pressure gradient, i.e., mean arterial pressure minus the CSF pressure, is reduced.

It must be remembered that the flow measure- ments obtained in this study are of the inflow to the brain and do not reflect changes in the intracranial distribution of flow. For example, the cortical veins may be more collapsible than the deeper vein structures such as the vein of Galen. If this is true, then elevation in CSF pressure may easily alter the normal pattern of distribution of the cerebral blood flow.

A second pertinent finding was that in our group flow was not significantly decreased until the CSF pressure was elevated to approximately 1.8 times the control pressure. This finding is also in keeping with the results of Kety and co-workers (4) and Ferris (3). In 13 patients, 12 of whom had a diagnosis of brain tumor, Kety and co-workers (4) found that in only those subjects in whom the CSF pressure was greater than $450 \mathrm{~mm} \mathrm{H}_{2} \mathrm{O}$ was cerebral blood flow depressed. Similarly, Ferris (3) noted in two subjects that flow was unchanged until the CSF pressure was greater than $350 \mathrm{~mm}$ $\mathrm{H}_{2} \mathrm{O}$. In explaining this finding, Kety and coworkers (4) postulated that a compensatory rise in arterial pressure occurs following increase in intracranial pressure, and up to a critical level of $450 \mathrm{~mm} \mathrm{H} \mathrm{H}_{2} \mathrm{O}$ this mechanism is sufficient to keep the cerebral blood flow constant. However, in the present study, no change occurred in either the arterial blood pressure or heart rate during the acute elevation of CSF pressure. Evans and co-workers also previously found no change in arterial blood pressure when the CSF pressure was acutely raised to levels below diastolic blood pressure (17). Thus, at these acutely increased CSF pressure levels flow is not reduced to the point at which hypertension occurs secondary to medullary ischemia. The existence of a critical level above which the CSF pressure must rise before flow is reduced may be partially explained by considering the relation between the two major areas of cerebral blood flow resistance as described above. As the CSF pressure rises, pressure within the cerebral veins within the subarachnoid space will also rise; however, this can take place only by allowing the pressure within the arterioles, i.e., approximately $400 \mathrm{~mm} \mathrm{H}_{2} \mathrm{O}$, to be transferred gradually to the veins. In this manner the normal pressure drop at the arteriolar-capillary level will be obliterated. Thus, a CSF pressure of approximately $400 \mathrm{~mm} \mathrm{H}_{2} \mathrm{O}$ must be attained before the total resistance to flow, normally present, is exceeded. 
In the foregoing discussion, the effects of active changes in cerebral vascular tone have not been mentioned. Undoubtedly such changes may occur in response to increased CSF pressure. For example, in four of these patients there was a slight but definite tendency for blood flow to return toward the control values despite a constant sustained elevation in the CSF pressure. This finding would imply that in these four patients there was "autoregulation" of the cerebral circulation in response to the increased pressure. In the remainder of the patients no evidence of autoregulation was observed. However, the maximal CSF pressure levels were maintained for only $5 \mathrm{~min}$ utes, and we cannot project these findings to rule out other adjustments in cerebral flow that may result from chronic CSF pressure elevation.

It should be noted that $\mathrm{PCO}_{2}$ values were not obtained during the time at which the CSF pressure was elevated. However, the lack of symptoms, and the fact that no change occurred in either heart rate or blood pressure, would imply that change in ventilation did not account for the effects on flow noted in these patients.

The lack of symptoms associated with elevations of the CSF pressure up to a mean level of $920 \mathrm{~mm}$ $\mathrm{H}_{2} \mathrm{O}$ in the present study is consistent with the results of other investigators. Wolff $(18,19)$ reported the absence of headache in four normal patients in whom the CSF pressure was artificially raised to levels between 680 and $850 \mathrm{~mm} \mathrm{H}_{2} \mathrm{O}$. Evans and co-workers (17) state that "we have elevated the intracranial pressure to $2000 \mathrm{~mm}$ of saline without the subject's awareness of any sensation."

The method used to increase the CSF pressure in the present study produced a generalized increase in pressure without displacement of the intracranial structures. Thus, the experimental situation is somewhat analogous to the clinical state of generalized cerebral edema, but differs from conditions in which the brain is also displaced, such as various intracranial tumors.

\section{Summary}

1. With an electromagnetic flowmeter and a pressure transducer, internal carotid arterial blood flow and pressure were measured continuously in 13 awake patients during incremental increases in cerebrospinal fluid (CSF) pressure to a level slightly below each patient's diastolic blood pressure.

2. The control value of mean flow for the group was $201 \mathrm{~cm}^{3}$ per second ( $\mathrm{SE} \pm 16$ ) obtained at a cerebrospinal fluid pressure of $190 \mathrm{~mm} \mathrm{H}_{2} \mathrm{O}$ ( $\mathrm{SE}$ $\pm 13)$.

3. Flow became significantly decreased at a CSF pressure of $380 \mathrm{~mm} \mathrm{H}_{2} \mathrm{O}(\mathrm{SE} \pm 11)$, and at a CSF pressure of $920 \mathrm{~mm} \mathrm{H}_{2} \mathrm{O}(\mathrm{SE} \pm 46)$ mean flow averaged $25 \%$ less than the control value.

4. No change was observed in the blood pressure, heart rate, electrocardiogram, or electroencephalogram.

5. In four patients, slight autoregulation of flow was found at the highest level of CSF pressure.

6. In three addition patients angiographic studies demonstrated that the cerebral veins lying within the subarachnoid space are not collapsed at a CSF pressure of $1,000 \mathrm{~mm} \mathrm{H}_{2} \mathrm{O}$.

\section{Acknowledgments}

We are indebted to Dr. William P. Wilson for interpreting the electroencephalograms. The excellent technical support rendered by Miss Corinna Thomas and Mr. Ezra Hayes is gratefully acknowledged.

\section{References}

1. Cushing, $H$. Concerning a definite regulatory mechanism of the vaso-motor centre which controls blood pressure during cerebral compression. Bull. Johns Hopk. Hosp. 1901, 12, 290.

2. Cushing, $H$. Some experimental and clinical observations concerning states of increased intracranial tension. Amer. J. med. Sci. 1902, 124, 375.

3. Ferris, E. B., Jr. Objective measurement of relative intracranial blood flow in man, with observations concerning hydrodynamics of craniovertebral system. Arch. Neurol. Psychiat. (Chic.) 1941, 41, 377.

4. Kety, S. S., H. A. Shenkin, and C. F. Schmidt. The effects of increased intracranial pressure on cerebral circulatory functions in man. $\mathrm{J}$. clin. Invest. 1948, 27, 493.

5. Green, H. D., C. E. Rapela, and M. C. Conrad. Resistance (conductance) and capacitance phenomena in terminal vascular beds. Autoregulatory control of resistance vessels in Handbook of Physiology, W. F. Hamilton, Ed. Washington, D. C., Amer. physiol. Soc., 1963, sect. 2, vol. 2, p. 942.

6. Williams, D., and W. G. Lennox. Cerebral bloodflow in arterial hypertension, arteriosclerosis, and 
high intracranial pressure. Quart. J. Med. 1939, 8, 185.

7. Kolin, A., and R. T. Kado. Miniaturization of electromagnetic blood flow meter and its use for recording of circulatory responses of conscious animals to sensory stimuli. Proc. nat. Acad. Sci. (Wash.) 1959, 45, 1312.

8. Snedecor, G. W., and W. G. Cochran. Statistical Methods Applied to Experiments in Agriculture and Biology, 5th ed. Ames, Iowa State College Press, 1956.

9. Dumke, P. R., and C. F. Schmidt. Quantitative measurements of cerebral blood flow in the macaque monkey. Amer. J. Physiol. 1943, 138, 421.

10. Kety, S. S., and C. F. Schmidt. The nitrous oxide method for the quantitative determination of cerebral blood flow in man: theory, procedure and normal values. J. clin. Invest. 1948, 27, 476.

11. Patel, D. J., J. C. Greenfield, Jr., W. C. Austen, A. G. Morrow, and D. L. Fry. Pressure-flow relationships in the ascending aorta and femoral artery of man. J. appl. Physiol. 1965, 20, 459.

12. Evans, J. P. Increased intracranial pressure. Surg. Clin. N. Amer. 1956, 36, 233.
13. Weinstein, J. D., T. W. Langfitt, and N. F. Kassell. Vasopressor response to increased intracranial pressure. Neurology (Minneap.) 1964, 14, 1118.

14. Permutt, S., and R. L. Riley. Hemodynamics of collapsible vessels with tone: the vascular waterfall. J. appl. Physiol. 1963, 18, 924.

15. Dawson, H. Physiology of the Ocular and Cerebrospinal Fluid. Boston, Little, Brown, 1956, pp. 346-351.

16. Wright, R. D. Experimental observations on increased intracranial pressure. Aust. N. Z. J. Surg. 1938, 7, 215.

17. Evans, J. P., F. F. Espey, F. V. Kristoff, F. D. Kimbell, and H. W. Ryder. Experimental and clinical observations on rising intracranial pressure. Arch. Surg. 1951, 63, 107.

18. Wolff, H. G. Experimentally induced elevation of intracranial pressure and headache observations in Headache and Other Head Pain. New York, Oxford University Press, 1963, p. 120.

19. Wolff, H. G. Intracranial pressure and headache associated with tumor of the brain in Headache and Other Head Pain. New York, Oxford University Press, 1963, p. 121. 